\title{
Statistical Quality Control (SQC) and Six Sigma Methodology: An Application of X-Bar Chart on Kuwait Petroleum Company
}

\author{
Muwafaq Alkubaisi ${ }^{1}$ \\ ${ }^{1}$ University of Bahrain, Bahrain \\ Correspondence: Dr. Muwafaq Alkubaisi, University of Bahrain, Bahrain. E-mail: drfendi@hotmail.com
}

Received: February 18, 2013

Accepted: March 13, $2013 \quad$ Online Published: May 12, 2013

doi:10.5430/ijba.v4n3p61

URL: http://dx.doi.org/10.5430/ijba.v4n3p61

\begin{abstract}
An x-bar chart is a statistical device used for the study and control of a process. Control charts based on the three sigma limits were produced and have been used effectively for a long time. In today's developed and developing countries, companies have introduced Six Sigma initiatives in their manufacturing processes which results in fewer defects, and identifies the causes of process variations. Companies employing Six Sigma initiatives are expected to produce 3.4 or less defects per million opportunities (DPMO) using the control limits suggested by Shewhart; then no point will fall outside the control boundaries because of reduction in variation. In this paper an attempt is made to construct a Six Sigma based on data collected from a petroleum company in Kuwait to produce an x-bar chart. Unfortunately, it seems there are some serious deficiencies in the production process since the value of $\mathrm{C}_{\mathrm{p}}$ and $\mathrm{C}_{\mathrm{pk}}$ are less than 1 which means the process is not capable of meeting its specifications.
\end{abstract}

Keywords: $\mathrm{X}$-bar chart, control chart, DPMO, three sigma, six sigma, $\mathrm{Cp}, \mathrm{C}_{\mathrm{pk}}$

\section{Introduction}

Since the days of Walter Shewhart, the father of modern statistical quality control, statistical knowledge has been considered necessary to understand the variability in product and process variables. It is also essential to find the means to minimize this variability, and consequently to produce quality products. The concept of Six Sigma (SS) was originally developed by Motorola in 1986 by an engineer, Bill Smith, the "Father of Six Sigma", who analyzed variations in outcomes of the company's internal procedures and reached the conclusion that by measuring variations it would be possible to improve the execution of the system. Six Sigma became well known after Jack Welch used it as the central focus of his business strategy at General Electric (GE) in 1995, and today it is widely used in many sectors of industry.

As the level of sigma rises, the level of variation decreases. In order to increase a company's process-sigma level, it should decrease the amount of variation that occurs in its process. The advantage of having less variation gives the company much higher predictability in the process, lowers costs as there is less waste and rework, better performance and longevity of products and services, and an eventual increase in customers' satisfaction.

Six Sigma is a statistical, scientific, and systematic approach to business process improvement and is considered to be one of the most important business strategies (Nakhai, B. \& Neves, J.S. 2009). The Six Sigma methodology targets the variation in processes, identifies and eliminates the defects or variations to improve quality and performance of business processes (Mortimer, A.L. 2006). This methodology uses sophisticated process analysis, data gathering, quality management and control and statistical techniques in an integrated framework (Soti, A., Shankar, R. \& Kaushal, O. 2010). It requires a process to produce 99.99966 percent of the products or service units to be defect free which means that there can only be 3.4 defected units per million opportunities (DPMO) (Aboelmaged, M.G. 2010, McCarty, T.D. \& Fisher, S.A. 2007). When adopting this methodology, we can say that if all business processes produce 99.99966 percent accurate or desired products or services, then the company will have a higher customer satisfaction rate, higher profits, improved business processes, much better return on investments, well satisfied stakeholders and have a competitive advantage.

To perform the Six Sigma methodology, we use two Six Sigma sub-methodologies: DMAIC and DMADV. The Six Sigma DMAIC process ( $\mathrm{D}=$ Define, $\mathrm{M}=$ Measure, $\mathrm{A}=$ Analyze, $\mathrm{I}=$ Improve, and $\mathrm{C}=\mathrm{Control}$ ) is an improvement methodology for processes that fall below specification and are looking for incremental improvement (Cheng, J. 
2007). The Six Sigma DMADV process ( $D=$ Define, $M=$ Measure, $A=$ Analyze, $D=$ Design, and $V=$ Verify) is an improvement methodology used to develop new processes at Six Sigma quality levels.

\section{Literature Review Analysis}

Six Sigma as an improvement methodology has received great attention in the literature over the last fifteen years (e.g. Bergman, B. \& Kroslid, D. 2000; Harry, M.J. (1998); Hellsten, U. \& Klefsjoe, B. (2000)).

From the statistical point of view, the term "Six Sigma" is defined as process having less than 3.4 defects per million opportunities DPMO or a success rate of 99.9997 percent (these computations assume a 1.5 sigma shift in the process mean, 1.5 to account for long-term variations) where sigma is a term used to represent the variation about the process mean (Antony. J. Banuelas. R. 2002). It is also defined in the business context as a business methodology used to improve business profitability, to improve the effectiveness and efficiency of all operations to meet or exceed customers' needs and expectations (Antony. J. Banuelas. R. 2002).

The Six Sigma program has been considered a radical approach to product and process quality improvement through the effective use of statistical methods (Harry, M. \& Schroeder, R. 2000; Eckes, G. 2000; Pande, P.S., Neuman, R.P. \& Cavanagh R.R. 2000).

One of the Six Sigma key renovations is the professionalization of quality management functions. For this reason, Six Sigma methodology identifies several key functions for its successful implementation: executive leadership (CEO and other members of top management); champions (they have the responsibility for Six Sigma development inside the organization); Master Black Belts or MBB (Black Belts' and Green Belts' guides with the projects development responsibility); Black Belts or BB (they apply Six Sigma methodology to specific projects); Green Belts or GB (as black belts, they have a good methodological preparation, although they work part-time on the project development due to other responsibilities inside the organization); DMAIC, DMADV and the belt system represent the core elements of a Six Sigma organization (Eckes, G. 2000).

Executives need to provide adequate resources for Six Sigma projects, and they also need to authorize Six Sigma project team members to take responsibility for the initiative.

Six Sigma is a formatted methodology that tries to achieve specific performance goals using some statistical tools and techniques. (Choo, A.S., Linderman, K.W., \& Schroeder, R.G. (2007a); Linderman, K.W., Schroeder, R.G., \& Choo, A.S. 2006).

Since Six Sigma originated within the quality management field (Linderman, K., Schroeder, R., Zaheer, S., \& Choo, A. 2003; Schroeder, R.G, Linderman, K., Liedtke, C., \& Choo, A.S. 2008) organizations can benefit from their Six Sigma initiatives if they frame it within the quality improvement paradigm. The Plan-Do-Check-Act (PDCA) cycle is well established within quality management (Choo, A.S., Linderman, K.W., \& Schroeder, R.G. 2007a; Deming, W.E. 1986; Shewhart, W.A. 1931, Shewhart, W.A. 1939).

Vision, resources, skills, action plans and incentives are necessary for effective Six Sigma implementation (Larson, A. 2003).

\section{Six Sigma Tool}

A Six Sigma tool assists a professional who knows how and when to use it. Once information is entered into a tool, a manager or technical worker can use the results to make decisions. Misinterpretation of a tool's results can lead to changes in production, data collection, internal controls, objectives, work assignments and other routines or decisions, which may hurt the organization's success.

The followings are some of the common tools used for Six Sigma methodology analysis:

- Control Plan (Control Chart)

- Thought Process Map

- Process Map

- Affinity Diagram or Kawakita Jiro (KJ) method

- Measurement System Analysis (MSA)

- Cause and Effect Analysis (C\&E)

- Kano Analysis

- Poka Yoke or Mistake Proofing 
- Pareto Chart

- Supplier-Input-Process-Output-Customer Analysis (SIPOC Analysis)

- Document Control Program

- Be On Look Out (BOLO) List or List for Analysis of Process Map

- Scatter Diagram or Scatter Plot

- Quality Function Deployment (QFD), also known as House of Quality

- Ishikawa Diagram

- Failure Mode Effects Analysis (FMEA)

- Failure Mode and Effects Criticality Analysis (FMECA)

- Value Chain Map

- Histogram

\section{Concepts, Terminology and Formulas}

Understanding Six Sigma terminology is becoming more and more important nowadays as organizations are waking up to its benefits. Six Sigma offers a good theoretical mechanism for improving quality and reducing the number of defects.

\section{Upper specification limit (USL)}

It is the greatest amount specified by the producer for a process or product to have the acceptable performance. Mathematically we can calculate it using one of two equations:

$$
U C L=\overline{\bar{X}}+A_{2} \bar{R} \quad \text { OR } \quad U C L=\overline{\bar{X}}+A_{3} \bar{S}
$$

\section{Lower specification limit (LSL)}

It is the smallest amount specified by the producer for a process or product to have the acceptable performance. Mathematically we can calculate it using one of two equations:

$$
L C L=\overline{\bar{X}}-A_{2} \bar{R} \quad \text { OR } \quad L C L=\overline{\bar{X}}-A_{3} \bar{S}
$$

Upper control limit (UCL): which you get from your process.

Lower control limit (LCL): which you get from your process.

\section{Tolerance level (TL)}

It is the difference between USL and LSL, TL = USL-LSL

\section{Process capability (Cp)}

This is the ratio of tolerance level to six times standard deviation of the process.

$$
C_{p}=\frac{T_{L}}{6 \sigma}=\frac{U S L-L S L}{6 \sigma}
$$

\section{Estimated Standard deviation $(\sigma)$}

For many purposes standard deviation is the most useful measure of dispersion of a set of numbers. It is the root mean square value. There are many ways to estimate its value, for example, $\sigma=\frac{\bar{R}}{d_{2}}$ and $\sigma=\frac{\bar{s}}{C_{4}}$

\section{Quality Control Constant (I 6 $\sigma$ )}

The constant (I $6 \sigma$ to determine the control limits for Six Sigma based x-bar chart using Standard deviation.

\section{Process Capability (Cp)}

Process Capability is an important concept in today's competitive market where there is a challenge of producing high quality at minimum costs. This can be done using a systematic approach which is contained within what has been called a "Statistical Quality Control"; and process capability which is a segment of Statistical Quality Control. Process capability is very important as it allows quantification of how well a process can produce an acceptable product. 
Process capability study indicates whether a process is capable of producing virtually all conforming products. If a process is capable, then a statistical process control tool can be used to monitor the process.

\section{Definitions:}

Process: Process refers to a system of any cause; any combinations of which work is performed to produce given results.

Process Capability: Process Capability refers to normal behavior of a process when operating in a state of statistical control. It refers to the inherent ability of a process to produce similar parts for sustained periods under a given set of conditions.

Process Capability Indices: Process Capability can be expressed as a percent nonconforming or in terms of the natural spread related to specification spread.

Process Capability Study: this study is a systematic procedure for determining the capability of a process. It may include studies to improve the process, or in turn the capability of the process. Process capability studies are usually performed as a part of a process optimization effort.

Process Capability Study Steps:

1). Select Critical Parameters correlated to product fit/function.

2). Collect data

3). Establish control over the process

4). Analyze Process Data

5). Analyze source of variation

6). Establish process monitoring system

\section{Value of Cp Signifies process as}

$\mathrm{Cp}<1.0$ Process is not capable of meeting its specification.

$\mathrm{Cp}=1.0$ Process is marginally capable of meeting specifications.

$\mathrm{Cp}>1.0$ Process is capable of meeting the specification limits. Cpk assesses both accuracy and precision of the process.

$\mathrm{C}_{\mathrm{pk}}$ values greater than 1.33 are considered GOOD.

$\mathrm{C}_{\mathrm{pk}}$ values greater than 1.33 and equal to $\mathrm{Cp}$ are considered BEST.

$\mathrm{C}_{\mathrm{P}}=$ capability

$\mathrm{C}_{\mathrm{Pk}}=$ actual production

\begin{tabular}{|c|c|c|}
\hline$\underline{C p k}$ & Sigma Level & $\underline{\text { Process Yield }}$ \\
\hline 0.33 & 1 & $68.27 \%$ \\
\hline 0.67 & 2 & $95.45 \%$ \\
\hline 1.00 & 3 & $99.73 \%$ \\
\hline 1.33 & 4 & $99.99 \%$ \\
\hline 1.67 & 5 & $99.9999 \%$ \\
\hline 2.00 & 6 & 99.999998 \\
\hline
\end{tabular}

From a statistical point of view $\mathrm{Cp}$ is the result obtained from the division of the Difference of the Upper and Lower Spec. limits and Six Sigma. That is Cp $=(\mathrm{USL}-\mathrm{LSL}) / 6$ Sigma. This means comparing the segment or base of the curve to Six Sigma. $\mathrm{C}_{\mathrm{pk}}$ measures only one side of the curve or spec limit to the mean or target. This indicates that the process can be out of limits in the lower side or in the upper side (by defect or by excess). If $\mathrm{C}_{\mathrm{pk}}<1$ in the lower side, defects are common; the same happens in the upper region. If $\mathrm{C}_{\mathrm{pk}}>1$ in the lower side, defects are rare; the same happens in the upper region. The spec. limits have to be greater than the process limits for good quality. The spec. limits are engineered limits and the process limits are the output of the process which we are trying to control with 6 Sigma. That is why we say, "Predictably twice as good as what the customer wants".

Following is an illustration of the Cp concept: 


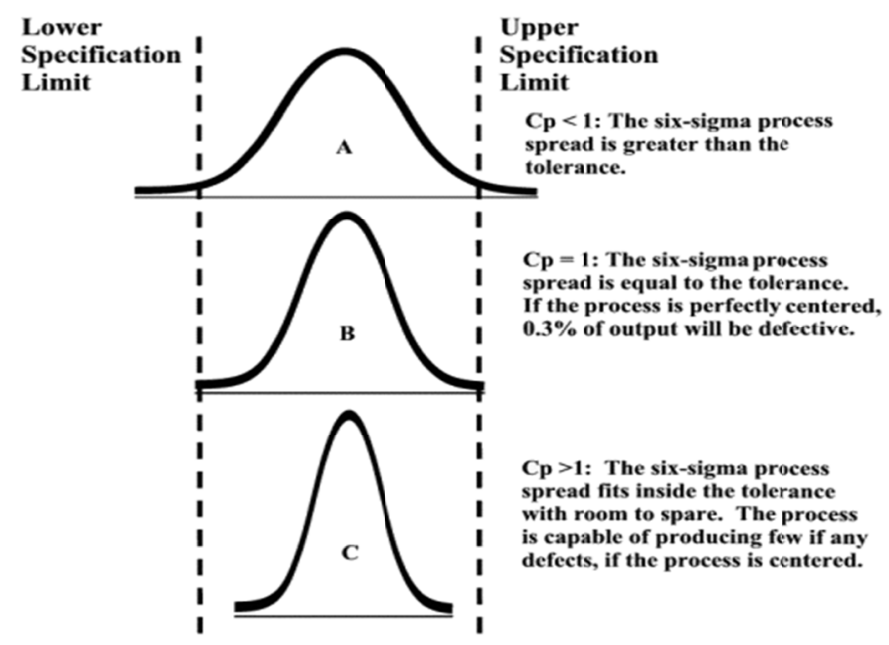

\section{Assumptions required for $\mathrm{C}_{\mathrm{p}}$ :}

- The underlying process is stable and in statistical control.

- The measurements are normally distributed.

- The measurement errors are negligible.

\section{Construction of Six Sigma Based Control Chart for $\bar{x}$ Chart Using Standard Deviation $\sigma_{6 \sigma}$}

In order to calculate the Six Sigma based control chart for the $\mathrm{x}$-bar chart limits, we need to fix the tolerance level $\left(\mathrm{T}_{\mathrm{L}}\right)$ and process capability $(\mathrm{CP})$ to produce the process standard deviation $\left(\sigma_{6 \sigma}\right)$ using a specified table designed for this purpose. Apply the value of $\left(\sigma_{6 \sigma}\right)$ in the control $\left(\overline{\bar{x}} \pm I_{6 \sigma} \sigma_{6 \sigma}\right)$ limits to calculate the control limits for the Six Sigma using Standard deviation. The value of $\left(I_{6 \sigma}\right)$ is obtained using $\mathrm{P}\left(\mathrm{z} \leq z_{6 \sigma}=1-\alpha_{1}\right.$, where $\alpha_{1}=3.4 \times 10^{-6}$ and $\mathrm{z}$ is a standard normal variate. For a specified $\mathrm{T}_{\mathrm{L}}$ and $\mathrm{CP}$ of the process, the value of $\sigma$ (termed as $\sigma_{6 \sigma}$ ) is calculated

from $C_{p}=\frac{T_{L}}{6 \sigma}$ using a $\mathrm{C}$ program or table for various combinations of $\mathrm{T}_{\mathrm{L}}$ and CP. Further the value of $\left(I_{6 \sigma}\right)$ is also obtained using the procedure given above and presented in a table for various sample size. The control limits for Six Sigma based control chart for the $x$ chart using Standard deviation can be calculated as follow:

$$
\begin{gathered}
\mathrm{UCL}_{6 \sigma}=\overline{\overline{\mathrm{x}}}+\mathrm{I}_{6 \sigma} \sigma_{6 \sigma} \\
\text { Central Line } \mathrm{CL}_{6 \sigma}=\overline{\overline{\mathrm{x}}} \\
\mathrm{LCL}_{6 \sigma}=\overline{\overline{\mathrm{x}}}-\mathrm{I}_{6 \sigma} \sigma_{6 \sigma}
\end{gathered}
$$

There are particular tables needed for the calculation of above equations, these are as follow:

- Table to determine the value of $\mathrm{I}_{6 \sigma}$ for a specified sample size.

- Table to calculate $\left(\sigma_{6 \sigma}\right)$ values for a specified CP and TL.

- Table to give the factors (values) of $\mathrm{d}_{2}$ and $\mathrm{C}_{4}$ for specified sample size.

- Table of control chart constants to give us the values of $\mathrm{A}_{2}$ and $\mathrm{A}_{3}$.

\section{The Relationship between Six Sigma Costs and Savings}

One of the aims of Six Sigma methodology is to reduce costs and increasing sales. Using Six Sigma requires an investigation of training methods and the organization's infrastructure.

Companies who invented and refined Six Sigma methodology like Motorola, Allied Signal, GE and Honeywell can shine the light on Six Sigma methodology achievement. Motorola claims they invented Six Sigma in 1986. Allied Signal adopted Six Sigma in 1994; GE, in 1995. The most critical issue is: how much financial obligation does Six Sigma require and what size of financial benefit can be gained? 
There are very few companies that have gained recognition for success with their Six Sigma methodologies, even though there are more than 500 who have applied the methods, with the exception of the big five companies; namely, Motorola, GE, Honeywell (formerly Allied Signal), Ford and Caterpillar.

As shown in Table 1 below, these companies have average annual revenue of nearly $\$ 36$ billion during the years in Six Sigma. A review of this table shows that Six Sigma savings can clearly be significant to a company. The savings, as a percentage of revenue, vary from 1.2 percent to 4.5 percent. As GE's 1996 annual report states, "It has been estimated that less than Six Sigma quality, i.e., the three-to-four Sigma levels that are average for most U.S. companies, can cost a company as much as 10-15 percent of its revenues. 1.2-4.5 percent of revenue is significant and should be well studied by any CEO."

Table 1. Six sigma cost and savings by company

\begin{tabular}{|c|c|c|c|c|c|}
\hline Year & Revenue (\$B) & Invested (\$B) & \% Revenue Invested & Savings (\$B) & \% Revenue Savings \\
\hline \multicolumn{6}{|c|}{ Motorola } \\
\hline 1986-2001 & 356.9(e) & ND & - & 161 & 4.5 \\
\hline \multicolumn{6}{|c|}{ Allied Signal } \\
\hline 1998 & 15.1 & ND & - & 0.52 & 3.3 \\
\hline \multicolumn{6}{|c|}{ GE } \\
\hline 1996 & 79.2 & 0.2 & 0.3 & 0.2 & 0.2 \\
\hline 1997 & 90.8 & 0.4 & 0.4 & 1 & 1.1 \\
\hline 1998 & 100.5 & 0.5 & 0.4 & 1.3 & 1.2 \\
\hline 1999 & 111.6 & 0.6 & 0.5 & 2 & 1.8 \\
\hline 1996-1999 & 382.1 & 1.6 & 0.4 & 4.43 & 1.2 \\
\hline \multicolumn{6}{|c|}{ Honeywell } \\
\hline 1998 & 23.6 & ND & - & 0.5 & 2.2 \\
\hline 1999 & 23.7 & ND & - & 0.6 & 2.5 \\
\hline 2000 & 25.0 & ND & - & 0.7 & 2.6 \\
\hline 1998-2000 & 72.3 & ND & - & 1.84 & 2.4 \\
\hline \multicolumn{6}{|c|}{ Ford } \\
\hline $2000-2002$ & 43.9 & ND & - & 16 & 2.3 \\
\hline
\end{tabular}

Key: $\$ B=\$$ Billions, United States(e) = Estimated, Yearly Revenue 1986-1992 Could Not Be Found ND = Not Disclosed

Note: Numbers Are Rounded To The Nearest Tenth

\section{Source: http://www.isixsigma.com}

Noticeable improvements can be shown when we move from one sigma level to another level. Improvements associated with moving towards Six Sigma have a huge effect on the bottom line savings and costs. Consider the following examples as depicted by Ron D. Snee, Roger W. Hoerl 2002: 


$$
\text { Four Sigma Methodology }
$$

You would be without hot water for more than 54 hours a year.

Your lights would be out for an hour a week.

Your telephone will be without service for more than four hours a month

Six out of every 1,000 invoices will contain incorrect information.

Approximately six out of every 1,000 packages processed will be outside of specifications. [check numbers here]

Six out of every 1,000 design elements relating to a new product are flawed before the product is fully commercialized.

You would spend 37 minutes in the repair garage for every 100 hours you operate the car.

\section{Case Study}

Data were collected from the Kuwait Oil Company (KOC) - Lubricating Grease Department in order to study the size of the product (Liters) during different times of the day and weather; the fluctuations in the size are within the company specifications. The sampling took place on different days and at different times of each day. Sample sizes of 5 containers were drawn during 20 observations per day for three different days. The designated standard size decided by the company was 45 liters with plus minus 3 liters (i.e.: Max 48 liters and Min 42 liters).

The samples values are listed in Appendix 1.

The next step was to draw an x-bar chart and Range chart. Calculations for the upper and lower boundaries for both charts were calculated and the estimated standard deviation was also calculated using Excel and Minitab Package. Four Graphs (Day-1, Day-2, Day-3, and Days $1 \& 3$ ) were designed and are presented.

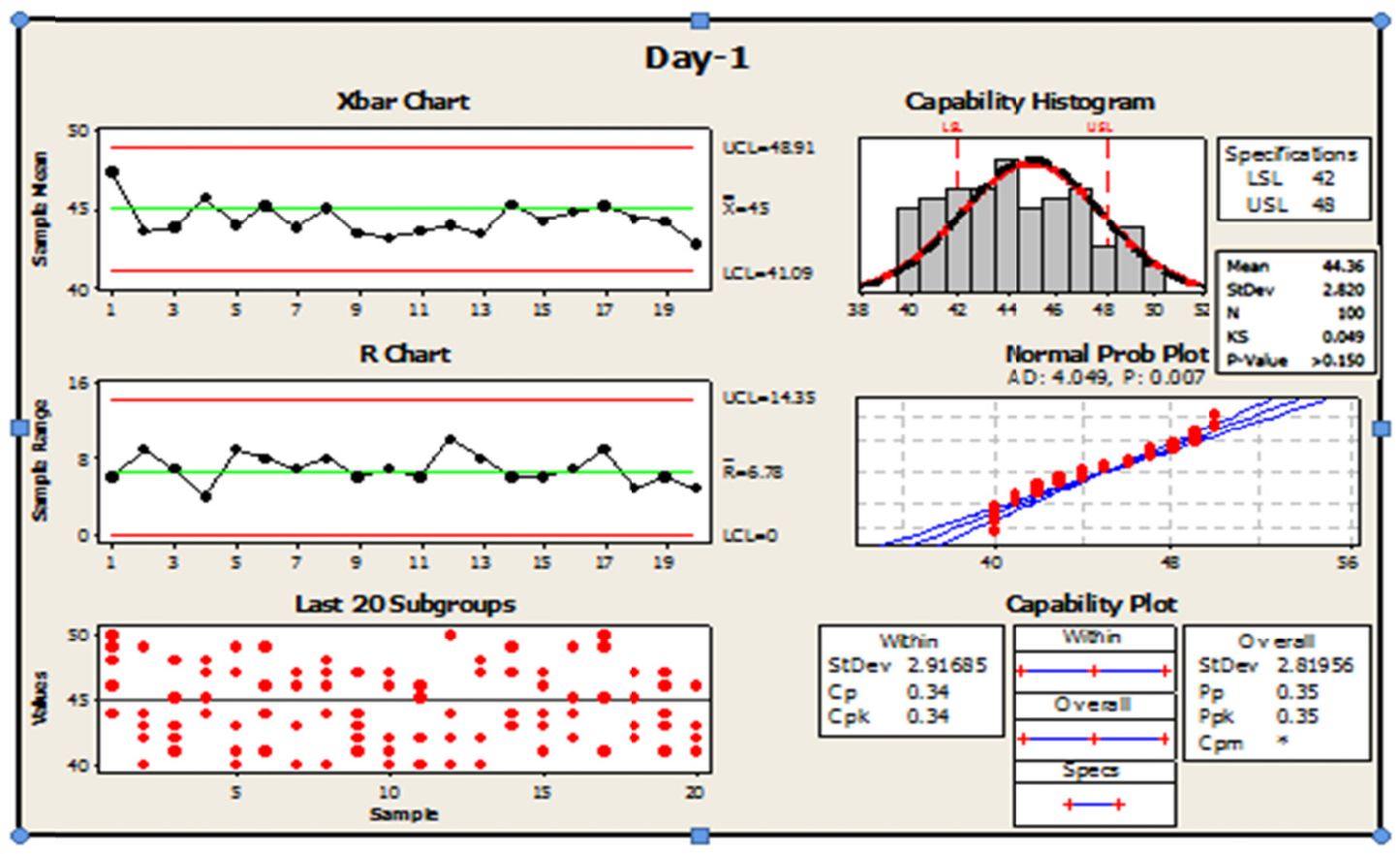



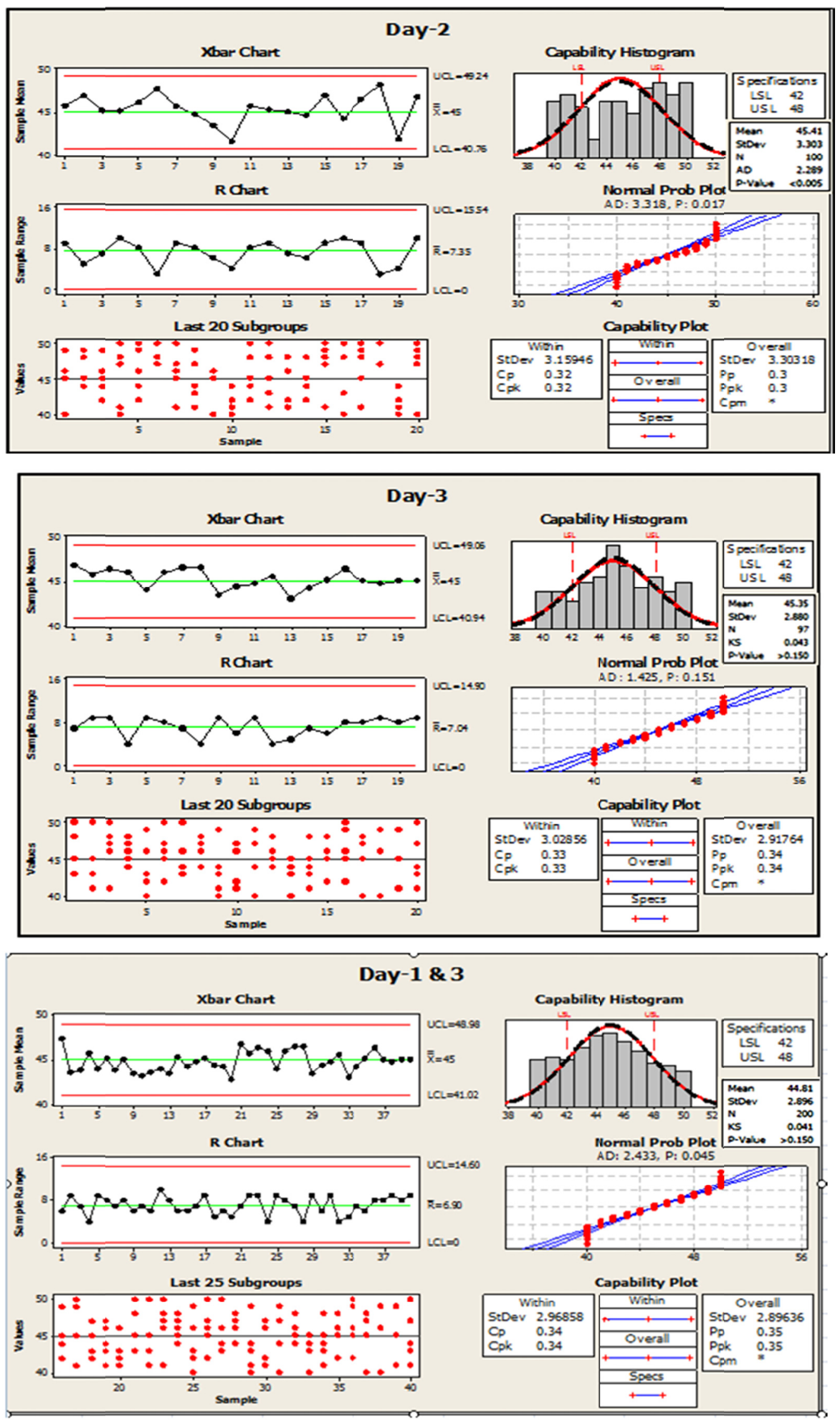


\section{Data Analyses and Findings}

1) Plotting values of averages to produce an $x$-bar chart using a three sigma chart for each day shows that the average production within the upper and lower limits, even though there are few observations, was above 48 liters and below 42 liters specifications.

2) The value of sigma for each of the three days is high (around 3). This means that the standard deviation is very close to the tolerance of the company of \pm 3 liters.

3) This shows simply that the production is only one sigma away from the mean which is not a good quality indicator.

4) One of the most important assumptions that must be met in the quality control analysis is that the distribution of the production should follow normal distribution. A Kolmogorov-Smirnov test for normality was executed on each of the three days' data and showed that Day 2 is not following normal distribution (i.e.: p-value $<0.05$ ).

5) An attempt was made to amalgamate data of Days 1 and 3 in order to isolate the non-normality of Day 2. The Kolmogorov-Smirnov test was performed on this data and showed the normality existed. (i.e.: p-value $>0.05$ ).

6) Day $1 \& 3$ production data is within the limits of the $\mathrm{x}$-bar chart, but the estimated standard deviation for the process is very high (around 3 liters).

7) It is noticed from all outputs above that the value of $C_{p}$ and $C_{p k}$ are less than 1 , which indicates the Process is not capable of meeting its specification. This should be studied carefully to determine why it is not able to meet the specification set by the company.

8) Studying the outputs of the three days' data, it is evident that there was no consistency in the production. Day 1 data produced only two points above the mean which means the production is significantly below the average set by the company. Whereas, in Day 2 it was a 50-50 case and day 3 data showed 9 observations below average.

9) For the amalgamated data of Days $1 \& 3,15$ of the 40 observations fall below the average. But still $\mathrm{C}_{\mathrm{p}}$ and $\mathrm{C}_{\mathrm{pk}}$ are below 1, which allows us to conclude that Process is not capable of meeting its specification.

10) It is very clear from the comparison between the $x$-bar charts done with Three Sigma and where the process is centered with reduced variation (Six Sigma), many points fall outside the control limits. This indicates that the process is not at the level expected. So a correction in the process is definitely required to reduce the variations, and specifically the standard deviation of the process.

\section{References}

Aboelmaged, M.G. (2010). Six Sigma quality: a structured review and implications for future research. International Journal of Quality \& Reliability Management, 27(3). http://dx.doi.org/10.1108/02656711011023294

Amabile, T.M., \& Gryskiewicz, S.S. (1987). Creativity in the R\&D laboratory. Greensboro, NC: Center for Creative Leadership.

Antony. J., \& Banuelas. R. (2002). Key ingredients for the effective implementation of Six Sigma program. Measuring Business Excellence, 6(4), ABI/INFORM Global. http://dx.doi.org/10.1108/13683040210451679

Bergman, B., \& Kroslid, D. (2000). Six Sigma - a revival of the profound knowledge of variation. Proceedings of the 3rd International Conference on Building People and Organizational Excellence, (Aarhus, Denmark).

Caulcutt, R. (2001). Why is Six Sigma so successful? Journal of Applied Statistics, 28, 301-306. http://dx.doi.org/10.1080/02664760120034045

Cheng, J. (2007). Six Sigma and TQM in Taiwan: An empirical study. Quality Management Journal, 14(2).

Choo, A.S., Linderman, K.W., \& Schroeder, R.G. (2007a). Method and context perspectives on learning and knowledge creation in quality management. Journal of Operations Management, 25.

Choo, A.S., Linderman, K.W., \& Schroeder, R.G. (2007b). Method and psychological effects on learning behaviors and knowledge creation in quality improvement projects. Management Science, 53.

Deming, W.E. (1986). Out of crisis. Cambridge, MA: MIT Press.

Eckes, G. (2000). The Six Sigma Revolution: How General Electric and Others Turned Process into Profits. John Wiley \& Sons, New York, NY.

Feld, K.., \& Stone, W. (2002). Using Six Sigma to change and measure improvement. Performance Improvement, 4l(9). http://dx.doi.org/10.1002/pfi.4140410908 
Harry, M.J. (1998). Six Sigma: a breakthrough strategy for profitability. Quality Progress.

Harry, M., \& Schroeder, R. (2000). Six Sigma: The breakthrough management strategy revolutionizing the world's top corporations. New York: Currency Publishers.

Hellsten, U., \& Klefsjoe, B. (2000). TQM as a management system consisting of values, techniques and tools. The TQM Magazine, 12. http://dx.doi.org/10.1108/09544780010325822

Larson, A. (2003). Demystifying Six Sigma: A company wide approach to process improvement. New York: American Management Association (AMA).

Linderman, K., Schroeder, R., Zaheer, S., \& Choo, A. (2003). Six Sigma: A goal theoretic perspective. Journal of Operations Management, 21. http://dx.doi.org/10.1016/S0272-6963(02)00087-6

Linderman, K.W., Schroeder, R.G., \& Choo, A.S. (2006). Six Sigma: The role of goals in improvement teams. Journal of Operations Management, 24. http://dx.doi.org/10.1016/j.jom.2005.08.005

McCarty, T.D., \& Fisher, S.A. (2007). Six Sigma: it is not what you think. Journal of Corporate Real Estate, 9(3). http://dx.doi.org/10.1108/14630010710845767

Mortimer, A.L. (2006). Six Sigma: effective handling of deep rooted quality problems. Assembly Automation, 26(3).

Nakhai, B., \& Neves, J.S. (2009). The challenges of Six Sigma in improving service quality. International Journal of Quality \& Reliability Management, 26(7). http://dx.doi.org/10.1108/02656710910975741

Pande, P.S., Neuman, R.P., \& Cavanagh R.R. (2000). The Six Sigma Way: How GE, Motorola, and other top companies are honing their performance. New York: McGraw Hill.

Ron D. Snee, \& Roger W. Hoerl. (2002, November 11). Leading SIX SIGMA A Step-by-Step Guide Based on Experience with GE and other Six Sigma Companies ( $1^{\text {st }}$ ed.). FT Press, New Jersey USA.

Schroeder, R.G., Linderman, K., Liedtke, C., \& Choo, A.S. (2008). Six Sigma: Definition and underlying theory. Journal of Operations Management, 26.

Shewhart, W.A. (1931). Economic control of quality of manufactured product. New York: D. Van Nostrand.

Shewhart, W.A. (1939). Statistical method from the viewpoint of quality control. Washington, DC: The Graduate School, Department of Agriculture.

Soti, A., Shankar, R., \& Kaushal, O.P. (2010). Modeling the enablers of Six Sigma using interpreting structural modeling. Journal of Modelling in Management, 5(2).

Wessel, G. (2003). A Comparison of Traditional TQM Methodologies with the Six Sigma Approach for Quality Management. Six- Sigma-Quality.de, Hamburg. Retrieved 2008, from www.wesselgo.de/sixsigma/reference/SSQ2_Difference_TQM_SixSigma.pdf 
Appendix 1. Control constants used for the chart limits calculations

$$
\begin{aligned}
& \text { A2 }=0.577 \\
& \text { D3 }=0.000 \\
& \text { D4 }=\mathbf{2 . 1 1 5}
\end{aligned}
$$

\begin{tabular}{|c|c|c|c|c|c|c|c|c|}
\hline $\begin{array}{c}\text { Observation } \\
\text { Day-1 }\end{array}$ & 1 & 2 & 3 & 4 & 5 & $\begin{array}{c}\text { Sample } \\
\text { Average }\end{array}$ & $\begin{array}{c}\text { Sample } \\
\text { Range }\end{array}$ & $\begin{array}{c}\text { Sample } \\
\text { SD }\end{array}$ \\
\hline 1 & 44 & 46 & 50 & 48 & 49 & 47.40 & 6.00 & 2.41 \\
\hline 2 & 49 & 43 & 42 & 40 & 44 & 43.60 & 9.00 & 3.36 \\
\hline 3 & 45 & 41 & 48 & 43 & 42 & 43.80 & 7.00 & 2.77 \\
\hline 4 & 48 & 44 & 47 & 45 & 45 & 45.80 & 4.00 & 1.64 \\
\hline 5 & 47 & 40 & 49 & 41 & 43 & 44.00 & 9.00 & 3.87 \\
\hline 6 & 41 & 49 & 46 & 46 & 44 & 45.20 & 8.00 & 2.95 \\
\hline 7 & 43 & 46 & 43 & 47 & 40 & 43.80 & 7.00 & 2.77 \\
\hline 8 & 44 & 47 & 46 & 48 & 40 & 45.00 & 8.00 & 3.16 \\
\hline 9 & 47 & 44 & 43 & 41 & 42 & 43.40 & 6.00 & 2.30 \\
\hline 10 & 46 & 47 & 40 & 41 & 42 & 43.20 & 7.00 & 3.11 \\
\hline 11 & 42 & 45 & 46 & 45 & 40 & 43.60 & 6.00 & 2.51 \\
\hline 12 & 50 & 44 & 42 & 40 & 44 & 44.00 & 10.00 & 3.74 \\
\hline 13 & 40 & 42 & 48 & 47 & 40 & 43.40 & 8.00 & 3.85 \\
\hline 14 & 47 & 44 & 49 & 43 & 44 & 45.40 & 6.00 & 2.51 \\
\hline 15 & 43 & 41 & 46 & 47 & 44 & 44.20 & 6.00 & 2.39 \\
\hline 16 & 44 & 42 & 44 & 49 & 45 & 44.80 & 7.00 & 2.59 \\
\hline 17 & 45 & 41 & 50 & 49 & 41 & 45.20 & 9.00 & 4.27 \\
\hline 18 & 45 & 47 & 43 & 42 & 45 & 44.40 & 5.00 & 1.95 \\
\hline 19 & 46 & 43 & 44 & 41 & 47 & 44.20 & 6.00 & 2.39 \\
\hline 20 & 42 & 46 & 42 & 43 & 41 & 42.80 & 5.00 & 1.92 \\
\hline \multicolumn{6}{|c|}{ Grand } & 44.36 & 6.95 & 2.8238 \\
\hline \multicolumn{9}{|c|}{ Estimated Sigma $=$ R-Bar $/ d_{2}=2.988$} \\
\hline \multicolumn{6}{|c|}{ Upper Control Limit (UCL) } & 48.37 & 14.70 & \\
\hline \multicolumn{6}{|c|}{ Center Line } & 44.36 & 6.95 & \\
\hline \multicolumn{6}{|c|}{ Lower Control Limit (LCL) } & 40.35 & $\mathbf{0 . 0 0}$ & \\
\hline $\begin{array}{c}\text { Observation } \\
\text { Day-2 }\end{array}$ & 1 & 2 & 3 & 4 & 5 & $\begin{array}{c}\text { Sample } \\
\text { Average }\end{array}$ & $\begin{array}{l}\text { Sample } \\
\text { Range }\end{array}$ & $\begin{array}{l}\text { Sample } \\
\text { SD }\end{array}$ \\
\hline 1 & 45 & 46 & 40 & 49 & 49 & 45.80 & 9.00 & 3.70 \\
\hline 2 & 49 & 44 & 48 & 49 & 45 & 47.00 & 5.00 & 2.35 \\
\hline 3 & 42 & 45 & 49 & 44 & 46 & 45.20 & 7.00 & 2.59 \\
\hline 4 & 41 & 50 & 40 & 48 & 47 & 45.20 & 10.00 & 4.44 \\
\hline 5 & 44 & 42 & 49 & 46 & 50 & 46.20 & 8.00 & 3.35 \\
\hline 6 & 50 & 47 & 47 & 48 & 47 & 47.80 & 3.00 & 1.30 \\
\hline 7 & 41 & 47 & 45 & 50 & 46 & 45.80 & 9.00 & 3.27 \\
\hline 8 & 49 & 47 & 43 & 41 & 44 & 44.80 & 8.00 & 3.19 \\
\hline 9 & 46 & 46 & 40 & 45 & 40 & 43.40 & 6.00 & 3.13 \\
\hline 10 & 40 & 41 & 42 & 44 & 41 & 41.60 & 4.00 & 1.52 \\
\hline 11 & 44 & 48 & 45 & 42 & 50 & 45.80 & 8.00 & 3.19 \\
\hline
\end{tabular}

Data collected for 3 days' production 


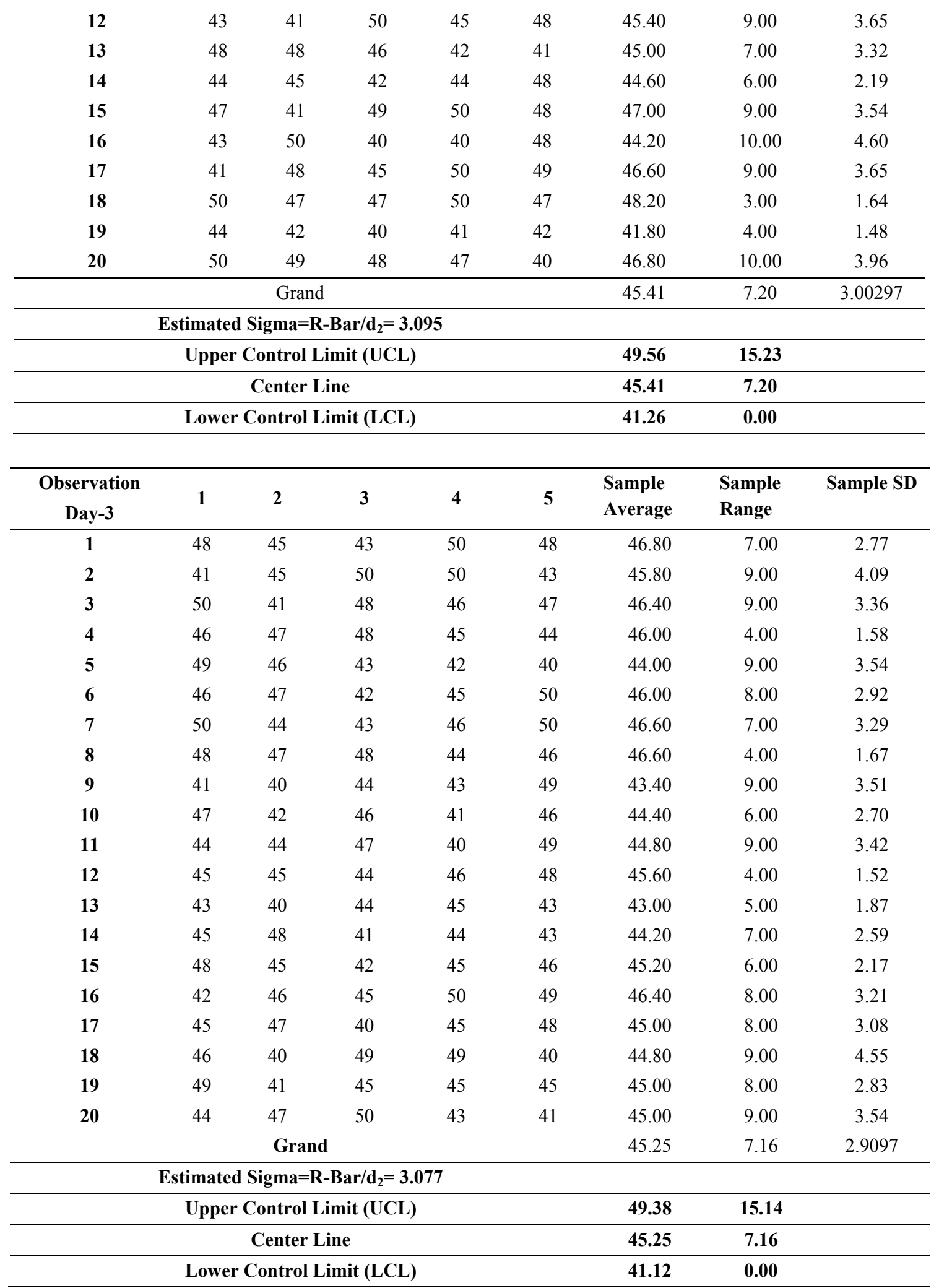

